\title{
Game-theoretic Approach to Electricity Retail Pricing Design for Demand Response Management in Russian Regions
}

\author{
Natalia Aizenberg ${ }^{1, *}$, Elena Stashkevich $^{2}$ \\ ${ }^{1}$ Department of Electric Power System, Melentiev Energy Systems Institute SB RAS, Irkutsk, Russia \\ ${ }^{2}$ Department of Power Supply and Electrical Engineering, Irkutsk National Research Technical University, Irkutsk, Russia
}

\begin{abstract}
The paper evaluates present-day retail market electricity rates in Russia from the standpoint of demand response i.e., how they motivate the customers to reduce demand during critical peak periods. For that purpose, the daily payments of different types of customers in RF regions are analyzed. It is shown that not all the retail market rates now in force stimulate the reduction of peak loads. A theoretical game model is proposed for the formation of electrycity rates for different types of consumers that incentivizes the demand response..
\end{abstract}

\section{Introduction}

Such peculiarities of electric power as simultaneous production and consumption, the impossibility of largescale electricity storage, difficulties of precise planning of electricity generation and consumption necessitate continuous maintenance of production and consumption equilibrium. Power plants traditionally play a major role in maintaining equilibrium. Also electricity markets are designed such that to give incentives to its players to maintain that equilibrium. But in the absence of special measures to manage the demand response, the electricity demand does not depend or to a little extent depends on the market prices as customers do not reduce electricity consumption if prices grow.

At present, with the emergence of smart power meters, advanced high-speed technologies for measurement, transfer, conversion and displaying the information on the current electricity consumption, the problem of demand response is solved based on the corresponding contracts of a load serving entity with individual power consumers; those contracts shall take into account economic benefits of both parties [1-6]. Load serving entities, based on the analysis of different power consumption facilities, identify such utilities that collectively allow almost $25 \%$ reduction of peak loads of the entity. Such utilities usually include air conditioners of large dwelling, commercial and administrative buildings, electric boilers, electric drives of pumps of water sprinkling systems in the rural areas, and others. After analysis and optimization of electricity consumption, the companies develop the demand-response electricity program, and set privileged rates for power consumers who agreed to participate in those programs.

$\mathrm{RF}$ is currently undertaking efforts to motivate customers to participate in raising the energy efficiency and leveling the load curves e.g., by the introduction of time-of-use (TOU) rates. The paper considers legally grounded rates that are most attractive for customers from the standpoint of their load response, i.e., rates that provide for payment for peak load or peak electricity consumption periods. They include a two-part rate with payment for electricity and capacity at peak loads of the power grid and TOU rate. The paper exploits the applicability of proposed rates for incentivizing the demand response (Section 1). The efficiency of the approach is exemplified by the assessment of daily electricity bills of two consumers of different types in different RF regions. Rates applied abroad [6-9] are considered in parallel, their incentives for demand response are assessed for customers that are similar to those in Russia. It is shown that RF rates, unlike foreign rates, do not always have the required incentives for reducing the peak loads. Studies on the foreign electricity markets that were undertaken recently propose an on-line demand response when a customer is capable to respond to variable power supply almost instantly [10-12]. In our opinion, such approach cannot be implemented in the conditions of the Russian market. We propose a pricing model that takes into account the interests of customers and the costs of a load serving entity for a month's time interval (Section 2).

\section{Comparison of the electricity pricing system for different types of customers in different RF regions}

Consider the electricity supply system of two customers. The first one includes loads of a student campus (Irkutsk) whose daily curve is typical to that of individuals (Table 1). This customer is assumed to be inactive, i.e., they do

* Corresponding author: zen@,isem.irk.ru 
Table 1. Daily load curves of two consumers: Campus and TV tower.

\begin{tabular}{|c|c|c|c|c|c|c|c|c|c|c|c|c|}
\hline Hrs & $\mathbf{0 : 0 0}$ & $\mathbf{1 : 0 0}$ & $\mathbf{2 : 0 0}$ & $\mathbf{3 : 0 0}$ & $\mathbf{4 : 0 0}$ & $\mathbf{5 : 0 0}$ & $\mathbf{6 : 0 0}$ & $\mathbf{7 : 0 0}$ & $\mathbf{8 : 0 0}$ & $\mathbf{9 : 0 0}$ & $\mathbf{1 0 : 0 0}$ & $\mathbf{1 1 : 0 0}$ \\
\hline Campus, kW & 51 & 44 & 38 & 35 & 34 & 30 & 32 & 46 & 48 & 49 & 48 & 47 \\
\hline $\begin{array}{c}\text { TV Tower, } \\
\text { kW }\end{array}$ & 166 & 164 & 163 & 163 & 163 & 167 & 167 & 168 & 170 & 169 & 172 & 169 \\
\hline Daily zone & $\begin{array}{c}\text { night- } \\
\text { time }\end{array}$ & $\begin{array}{c}\text { night- } \\
\text { time }\end{array}$ & $\begin{array}{l}\text { night- } \\
\text { time }\end{array}$ & $\begin{array}{l}\text { night- } \\
\text { time }\end{array}$ & $\begin{array}{l}\text { night- } \\
\text { time }\end{array}$ & $\begin{array}{l}\text { night- } \\
\text { time }\end{array}$ & $\begin{array}{l}\text { night- } \\
\text { time }\end{array}$ & $\begin{array}{l}\text { night- } \\
\text { time }\end{array}$ & $\begin{array}{c}\text { semi- } \\
\text { peak }\end{array}$ & peak & peak & peak \\
\hline Hrs & $\mathbf{1 2 : 0 0}$ & $\mathbf{1 3 : 0 0}$ & $\mathbf{1 4 : 0 0}$ & $\mathbf{1 5 : 0 0}$ & $\mathbf{1 6 : 0 0}$ & $\mathbf{1 7 : 0 0}$ & $\mathbf{1 8 : 0 0}$ & $\mathbf{1 9 : 0 0}$ & $\mathbf{2 0 : 0 0}$ & $\mathbf{2 1 : 0 0}$ & $\mathbf{2 2 : 0 0}$ & $\mathbf{2 3 : 0 0}$ \\
\hline Campus, kW & 58 & 53 & 55 & 52 & 54 & 62 & 66 & 69 & 76 & 73 & 73 & 63 \\
\hline $\begin{array}{c}\text { TV Tower, } \\
\text { kW }\end{array}$ & 168 & 169 & 170 & 169 & 169 & 166 & 167 & 167 & 168 & 167 & 166 & 165 \\
\hline $\begin{array}{c}\text { Daily period } \\
\text { peak }\end{array}$ & $\begin{array}{c}\text { semi- } \\
\text { peak }\end{array}$ & $\begin{array}{c}\text { semi- } \\
\text { peak }\end{array}$ & $\begin{array}{c}\text { semi- } \\
\text { peak }\end{array}$ & $\begin{array}{c}\text { semi- } \\
\text { peak }\end{array}$ & $\begin{array}{c}\text { semi- } \\
\text { peak }\end{array}$ & peak & peak & peak & peak & $\begin{array}{c}\text { semi- } \\
\text { peak }\end{array}$ & $\begin{array}{c}\text { night- } \\
\text { time }\end{array}$ \\
\hline
\end{tabular}

not change their electricity consumption pattern if saving is not considerable. The second one is a small business customer and its demand is conditioned by a certain production facility. In our case, it is a daily load curve of a TV Tower (Irkutsk), (Table 1). Let us assume that this customer is interested in varying demand response. The second customer is larger than the first one. Both customers belong to a group with a low voltage load below $670 \mathrm{~kW}$. Such customers are legally offered several types of rates. The paper considers the main of them. They are 1PC (price category) rate (flat rate, i.e., the price for any unit of product is the same); $2 \mathrm{PC}$ rate (time-of-use (TOU) rate (differentiated by three day periods); and 3PC rate (a two-part rate that includes payment for capacity).

Load serving entity is interested in load response by consumers and, hence, it selects rates motivating the electricity consumption curve optimization. In this case, they are $2 \mathrm{PC}$ and $3 \mathrm{PC}$ rates. Some authors [3] consider that a two-part rate is most demand-response oriented one as prices within this rate vary from hour to hour, payment for power is related to a peak in the power grid, which creates an additional incentive to shift maximum consumption to other periods of the day. At the same time, the TOU rate is more understandable for a common customer owing to its simplicity. Therefore, both rates shall be well thought over to raise their efficiency and to have a stimulating effect at the retail market.
Further, we will discuss how legally priced rates work at the RF electricity market as regards selected consumers. For that purpose, we will analyze the ratio of electricity payment under all the three rates. It should be noted that the daily load curves of selected customers correspond to their averaged January load; therefore, all the rates we use in the calculation are January 2019 rates. Calculated is the aggregate bill for the month.

All the data on rates were taken from the websites of load serving entity in the corresponding RF regions where electricity is priced on the competitive base, i.e., for two price zones of the wholesale electricity market. As an example, Tables 2 and 3 present the data on rates for 1PC - 3PC for the following price zones: Siberia (Novosibirsk oblast) and European part of Russia (Moscow oblast). Rates are given without VAT.

Table 2. Data on the flat rates (1PC) and TOU rates s (2PC) specified by day periods (nighttime, semi-peak, peak).

\begin{tabular}{|l|l|l|l|l|}
\hline \multirow{2}{*}{ RF region } & \multirow{2}{*}{$\begin{array}{l}\text { 1PC, } \\
\text { Rub/MW.h }\end{array}$} & \multicolumn{3}{|c|}{ 2PC, Rub/MW.h } \\
\cline { 3 - 5 } & nighttime & $\begin{array}{l}\text { semi- } \\
\text { peak }\end{array}$ & peak \\
\hline $\begin{array}{l}\text { Novosibirsk } \\
\text { oblast }\end{array}$ & 3,861 & 2,922 & 3,977 & 7,298 \\
\hline $\begin{array}{l}\text { Moscow } \\
\text { oblast }\end{array}$ & 5,041 & 3,669 & 5,227 & 8,834 \\
\hline
\end{tabular}

Table 3. Data on two-part rate (3PC).

\begin{tabular}{|c|c|c|c|c|c|c|c|c|c|c|c|c|}
\hline \multicolumn{13}{|c|}{ Capacity rate, Rub/MW per month } \\
\hline \multicolumn{7}{|c|}{ Novosibirsk oblast } & \multicolumn{6}{|c|}{$656,357.4$} \\
\hline \multicolumn{6}{|c|}{ Moscow oblast } & & \multicolumn{6}{|c|}{$735,261.6$} \\
\hline \multicolumn{13}{|c|}{ Electricity rates, RUB/MW } \\
\hline Hours of the day & $\begin{array}{r}0: 00- \\
1: 00\end{array}$ & $\begin{array}{l}1: 00 \\
\text { AM- } \\
2: 00\end{array}$ & $\begin{array}{l}2: 00 \\
\text { AM- } \\
3: 00 \\
\end{array}$ & $\begin{array}{l}3: 00 \\
\text { AM- } \\
4: 00\end{array}$ & $\begin{array}{c}4: 00 \\
\text { AM- } \\
5: 00 \\
\end{array}$ & $\begin{array}{c}5: 00 \\
\text { AM- } \\
6: 00 \\
\end{array}$ & $\begin{array}{c}6: 00 \\
\text { AM- } \\
7: 00 \\
\end{array}$ & $\begin{array}{l}\text { 7:00 } \\
\text { AM- } \\
\text { 8:00 }\end{array}$ & $\begin{array}{l}\text { 8:00 } \\
\text { AM- } \\
\text { 9:00 } \\
\end{array}$ & $\begin{array}{c}\text { 9:00 } \\
\text { AM- } \\
\text { 10:00 }\end{array}$ & $\begin{array}{r}10: 00 \\
\text { AM- } \\
11: 00 \\
\end{array}$ & $\begin{array}{c}\text { 11:00 } \\
\text { AM- } \\
12: 00\end{array}$ \\
\hline Novosibirsk oblast & 2,973 & 2,952 & 2,918 & 2,886 & 2,871 & 2,868 & 2,877 & 2,889 & 2,908 & 2,952 & 2,992 & 3,023 \\
\hline Moscow oblast & 3,471 & 3,385 & 3,332 & 3,316 & 3,339 & 3,393 & 3,454 & 3,604 & 3,731 & 3,827 & 3,884 & 3,888 \\
\hline Hours of the day & $\begin{array}{c}12: 00 \\
\text { PM- } \\
13: 00\end{array}$ & $\begin{array}{c}1: 00 \\
\text { PM- } \\
14: 00 \\
\end{array}$ & $\begin{array}{c}2: 00 \\
\text { PM- } \\
15: 00\end{array}$ & $\begin{array}{c}3: 00 \\
\text { PM- } \\
16: 00 \\
\end{array}$ & $\begin{array}{c}4: 00 \\
\text { PM- } \\
17: 00 \\
\end{array}$ & $\begin{array}{c}5: 00 \\
\text { PM- } \\
18: 00 \\
\end{array}$ & $\begin{array}{c}6: 00 \\
\text { PM- } \\
\text { 19:00 } \\
\end{array}$ & $\begin{array}{c}\text { 7:00 } \\
\text { PM- } \\
\text { 20:00 } \\
\end{array}$ & $\begin{array}{c}\text { 8:00 } \\
\text { PM- } \\
\text { 21:00 } \\
\end{array}$ & $\begin{array}{c}\text { 9:00 } \\
\text { PM- } \\
\text { 22:00 } \\
\end{array}$ & $\begin{array}{c}10: 00 \\
\text { PM- } \\
23: 00 \\
\end{array}$ & $\begin{array}{c}\text { 11:00 } \\
\text { PM- } \\
\text { 0:00 } \\
\end{array}$ \\
\hline Novosibirsk oblast & 3,036 & 3,053 & 3,055 & 3,027 & 3,028 & 3,039 & 3,060 & 3,060 & 3,049 & 3,033 & 3,029 & 3,007 \\
\hline Moscow oblast & 3,877 & 3,881 & 3,881 & 3,868 & 3,885 & 3,947 & 3,947 & 3,934 & 3,896 & 3,844 & 3,679 & 3,524 \\
\hline
\end{tabular}




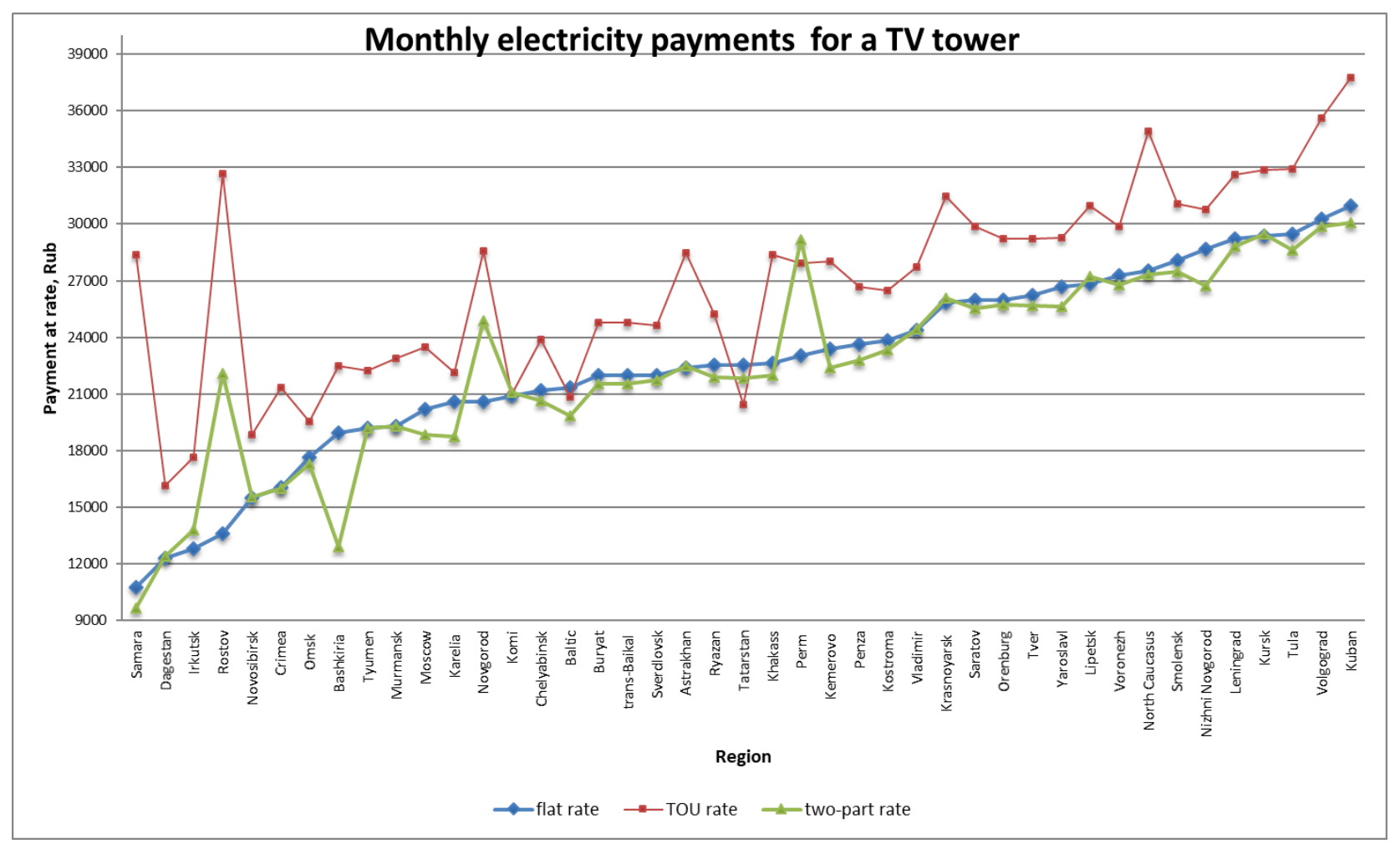

Fig. 1. Monthly electricity payments of TV tower under different rates.

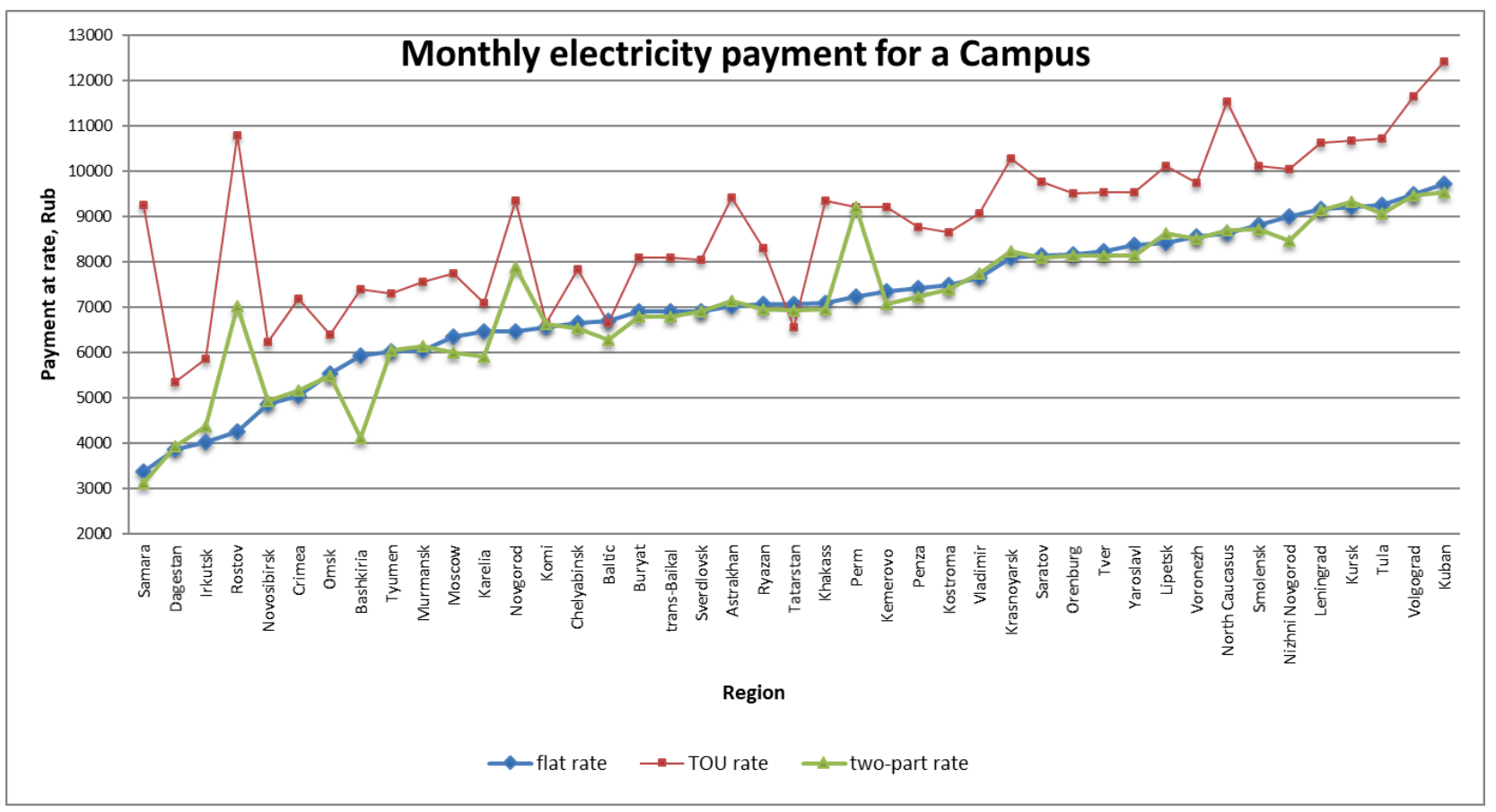

Fig. 2. Monthly electricity payment under different rates for a Campus.

For calculating the payment for electricity in January 2019, we used data on rates for Russian regions located in the price zones of the wholesale market. Figs. 1 and 2 show how changes the payment for the same type of customers in different regions of RF (Campus and TV Tower, respectively). The Figures reflect payment as per the flat rate (1PC) sorted in ascending order.
Figs. 1 and 2 demonstrate that the ratio between payments based on the rates in different RF regions may differ considerably. There are some important peculiarities:

1. We assume that $2 \mathrm{PC}$ and $3 \mathrm{PC}$ rates stimulate load reduction by a consumer in the peak hours. Therefore, that would be proper for those rates to be lower than rates without incentives (1PC) or to coincide with bills as per 
1PC. In the latter case, any measures taken to reduce the peak load would reduce payments based on demandresponse rates and a customer would prefer those rates as they would be more profitable for him. But, unfortunately, the described logical ratio of rates does not work for the selected customers.

2. TOU (2PC) rate, in our opinion, works poorly in the regions. Payments based on this rate for the selected types of consumers are almost everywhere higher than those based on the flat rate, and the extra charge makes from $13 \%$ to $150 \%$. To get benefits from the demand-response rate, the TV tower load shall be about $83 \%$ of the total daily load. Such changes in the load do not look realistic and, hence, neither potential consumer of this type would select this 'stimulating' rate. The conclusion on the Campus as a consumer is similar.

Table 4 gives data on excess payment under the demand-response rate versus flat rate for a TV Tower consumer in some regions. It also gives estimates of a possible reduction in the peak load against the existing one such that selection of the demand-response rate was attractive. It is obvious that the proposed option does not look realistic.

Table 4. Excess in payment under the demand-response rate (2PC) over the flat one (1PC).

\begin{tabular}{|l|c|c|c|}
\hline \multirow{2}{*}{ RF region } & \multicolumn{2}{|c|}{$\begin{array}{c}\text { Daily payment under the } \\
\text { rates : }\end{array}$} & \multirow{2}{*}{$\begin{array}{c}\text { Excess, } \\
\%\end{array}$} \\
\cline { 2 - 3 } & $\begin{array}{c}\text { 1PC, } \\
\text { Rub/MW.h }\end{array}$ & $\begin{array}{c}\text { 2PC, } \\
\text { Rub/MW.h }\end{array}$ & \\
\hline Irkutsk & 12,800 & 17,627 & 27 \\
\hline Krasnoyarsk & 25,828 & 31,485 & 18 \\
\hline Moscow & 20,215 & 23,505 & 14 \\
\hline Lipetsk & 26,841 & 30,989 & 13 \\
\hline Sverdlovsk & 22,007 & 24,650 & 11 \\
\hline Chelyabinsk & 21,167 & 23,904 & 11.5 \\
\hline Astrakhan & 22,390 & 28490 & 21 \\
\hline Volgograd & 30,267 & 35,604 & 15 \\
\hline
\end{tabular}

We assessed the scale of possible peak load shift by customers when selecting the demand-response rate (2PC) in order that it became profitable. Daily payment under the demand-response rate $(2 \mathrm{PC})$ in this case shall be less than daily payment under the flat rate (1PC). It turned out that the peak load for the TV Tower shall be changed by $83 \%$ and by $76 \%$ for the Campus (calculations were rate for Irkutsk and Moscow oblasts at load shift from the peak zone to the daytime zone). Those changes are not realistic. Hence, customers would never choose $2 \mathrm{PC}$ rate.

3. The ratios between two-part rate (3PC) and flat (1PC) rates for different regions of Russia are not similar. For example, in Irkutsk, Rostov, Novgorod, and Perm oblasts the payment under the flat rate turns out to be more preferable. In this case it makes no sense to select the stimulating two-part rate and undertake additional measures to respond. There are regions where $3 \mathrm{PC}$ rate is beneficial for customers. They are RF regions where payments under both rates coincide or are close, which stimulates energy saving measures for the peak load reduction.
4. Stimulating the $3 \mathrm{PC}$ rate is more attractive for $\mathrm{TV}$ Tower than for Campus In 11 regions payment at the two-part rate for Tower is lower than at the flat rate .

5. We can conclude that rates in the Russian regions do not always stimulate peak load reduction (it is especially true for TOU (2PC) rate), whereas principles and constraints of rate pricing are the same throughout RF. It is necessary to adjust the system of rates as a whole, and assign rates depending on the rates of other rates. The type of customers prevailing in the region shall be taken into account as well.

If we looked at the foreign practice of pricing at the retail sales market, we would notice that TOU rates prevail [8]. If we carefully investigate their rates, we will get a quite logical picture of rates ratio, and, hence, the working price-based incentives for load curve optimization.

Results for rates for selected by TV Tower and Campus in Ontario (USA) in winter 2019 [9] are given in Table 5. We can see that payments at the flat rate are lower than at TOU rate, which stimulates consumers to select this rate and to take active measures to reduce peak loads.

Table 5. Daily bills of TV Tower and Campus at rates valid in Ontario (Canada) in November, 2019.

\begin{tabular}{|c|c|c|c|}
\hline \multirow[b]{2}{*}{ Time of Use } & \multirow{2}{*}{$\begin{array}{l}\text { Rate, } \\
\$ / \mathrm{kWh}\end{array}$} & \multicolumn{2}{|c|}{ Daily payment, \$ } \\
\hline & & Campus & TV Tower \\
\hline Off peak & 0.101 & \multirow{3}{*}{1.83} & \multirow{3}{*}{5.77} \\
\hline Mid peak & 0.144 & & \\
\hline On peak & 0.202 & & \\
\hline Flat rate & 0.155 & 1.95 & 6.21 \\
\hline
\end{tabular}

Therefore, the ratio of rates in RF regions requires adjustment. In the third part of the article, we offer a model for rates assignment based on the specific loads of customers and costs of a load serving entity. Rates formed shall motivate consumers to reduce their peak load.

\section{A model for assigning the system of demand-response rates by the types of customers prevailing in the region}

In the previous section, we proved that rates in RF regions are priced such that one and the same customer might be stimulated to attake different activities. We also know that rates providing for payment for peak capacity or peak-demand time of electricity consumption have an incentivizing effect. At the Russian electricity market, they are $2 \mathrm{PC}$ and $3 \mathrm{PC}$ rates.

We considered two types of customers. The campus curve corresponds to that of common individuals who are difficult to be motivated to change their behavior. They are not completely rational and poorly respond to financial stimuli at the expense of convenience. Nevertheless, the habits of such customers may be changed with time (in the long-run), therefore, the availability of incentives in rates assigned to them is important. Another group of customers is more rational and will respond to financial incentives more willingly. A 
TV Tower is an example of such a customer: it is a small business interested in profit maximization, including owing to using energy saving measures.

Further, we propose a technique aimed at forming the rates that would stimulate customers to optimize their load curves, i.e., those customers that belong to a more rational type would select rates providing for payment for peak capacity or peak-demand time of electricity consumption. Such customers as individuals (households) do not need that, i.e., we assume that they may select a flat rather than the demand-response rate (1PC).

\subsection{Mathematical statement of the model}

Let the costs of the load serving entity be described by function $C(P)$. They are costs of purchasing electricity at the wholesale market and of its transfer to customers. They are assumed to have a standard form, i.e. constant and variable parts.

For simplification, let us consider the calculation of optimum rates for two different customers that is similar to calculations made in the previous section. The daily load curve of the first consumer corresponds to a standard household with peak loads in the morning and evening. This type of customer has a low total load. Besides, their preferences belong to 'limited rationality', i.e., their behavior is determined more by convenience than by financial incentives. The behavior of the second consumer is assumed to be similar to that of a mid-scale business. The load is higher than in the household, the load curve is determined by the production activity of the company, and a customer is ready to undertake measures to reduce power payments even at the expense of some inconvenience.

A load serving entity is interested in consumption optimization by customers, thus reducing the general costs of the grid, and it offers rates stimulating that. Realizing that large power customers (including production facilities) are easier to be motivated to apply energy saving measures, the rates shall be such that they were those customers who would select demand-response rates. In our case, they are TOU rates. Thus, the problem to be resolved by load serving entity is the maximization of profit provided that TOU rate is selected by a rational (larger) consumer. A flat rate, in this case, is formed based on the load serving entity costs and the permissible sale extra charge.

Let the load of the $i$-th customer be $P_{i}^{t}, i=\{1,2\}$. A vector of loads of customers is $P=\left(P_{1}, P_{2}\right)$, where $P_{i}=$ $\sum_{t} P_{i}^{t}$. Time $t$ changes a load of a consumer from hour to hour, but in the model, it is taken account of by time-ofuse periods $t \in\{N, H, M\}: N$ - nighttime period, $H-$ semi-peak period, and $M$ - peak period. $p_{L}$ - rate of a flat rate or $1 \mathrm{PC}$ rate. $p_{d}^{t}$ - rate of TOU rate $2 \mathrm{PC}$ depending on the time period $t$. The main objective of the load serving entity is profit maximization:

$$
\begin{gathered}
\pi\left(p_{L}, p_{d}^{t}, P\right) \equiv p_{L} \cdot \sum_{t} P_{1}^{t}+\sum_{t} p_{d}^{t} P_{2}^{t}-\sum_{t} C^{t}\left(P_{1}^{t}+\right. \\
\left.+P_{2}^{t}\right) \longrightarrow \max _{P_{1}^{t}, P_{2}^{t}, p_{L}, p_{d}^{t}, t \in\{N, H, M\}} \\
p_{L} \cdot \sum_{t} P_{2}^{t} \geq \sum_{t} p_{d}^{t} P_{2}^{t}
\end{gathered}
$$

$$
P_{i \min }^{t} \leq P_{i}^{t} \leq P_{i \max }^{t}, t \in\{N, H, M\}, i=\{1,2\} .
$$

A customer in his turn maximizes his practicality. This problem is not discussed here in the explicit form and it is assumed that a customer is interested in cost minimization. So that the load serving entity could not raise prices without control, the level of earnings is controlled by sales extra charge $S^{t}$ in each price period of the day $t \in\{N, H, M\}$.

$$
p_{L} \cdot P_{1}^{t}+p_{d}^{t} P_{2}^{t} \leq S^{t} \cdot\left(P_{1}^{t}+P_{2}^{t}\right), t \in\{N, H, M\} .
$$

Levels of rates for different types of customers will be separated by constraint (2). From the problem stated we get the following rules for rates assignment with an account of constraints on the sale extra charge:

1. TOU rate (2PC)

$$
M C^{t} \leq p_{d}^{t} \leq M C^{t} \frac{\sum_{t} P_{2}^{t}}{\sum_{t} P_{1}^{t}}, t \in\{N, H, M\},
$$

where $M C^{t}$ are marginal costs in the price period $t$.

2. The flat rate is the same for all the time periods (1PC).

$$
\frac{\sum_{t} p_{d}^{t} P_{2}^{t}}{\sum_{t} P_{2}^{t}} \leq p_{L} \leq S
$$

As is seen from (5), prices within the TOU rate can be rather close to marginal costs. Moreover, if a customer who has chosen that rate lowers the peak hour load, he will impact the level of costs and, hence, will reduce his payments for electricity. Those are stimulating properties of TOU rate in the long run. It is obvious that small customers have no considerable impact on the costs of the load serving entity. For using the above tool one can introduce structures that would aggregate small customers, for them to be able to participate in the demand response policy.

\subsection{An illustrative example}

Further, we give calculations made using the model for several RF regions. A possible adjustment of TOU rate for two consumers described in Section 2 is given as an example. Problem (1)-(4) was stated and solved for each region separately. It is assumed that only selected consumers (Campus and TV Tower) are in operation at the Russian electricity retail market. Costs taken into account in the model are assumed to be constant. In this particular case, the task is to balance rates such that the TOU rate would stimulate the reduction of peak load. And a customer, both small- and mid-scale one would have incentives to select that rate and to introduce in the long run the energy saving measures to additionally reduce payments under that rate.

Loads of two customers presented in Table 1 were used in the model. It should be mentioned that in those calculations we did not consider load optimization by customers, therefore, variables of consumption volumes $P_{1}^{t}, P_{2}^{t}, t \in\{N, H, M\}$ for the problem (1)-(4) are assumed to be constant. Costs of a load serving entity are also assumed to be constant. Objective of study has been 
formulated as follows: how rates for customers shall be adjusted (provided the load curves and load serving entity costs remain unchanged) so that new rates would stimulate peak load optimization and would not reduce the company's profit.

Company costs were calculated based on the average electricity price at the wholesale market for any day within the considered period (January 2019) with an account of the extra charge for electricity transmission services. Several selected regions were analyzed in terms of misbalance between payments at the flat (1PC) and TOU (2PC) rates. Rates of those rates are variables in problem (1)-(4). Constraint (4) was formulated in the following form. The profit of the energy company under load serving entity at new rates must not exceed that at previous rates. It should be kept in mind that a customer selects the rate that gives him more benefits. Under starting conditions as per those described in Section 2, both customers select the flat rate (1PC). Further, we will simulate circumstances when one customer (TV Tower) is interested in the TOU rate (2PC), whereas Campus may adhere to the flat rate (1PC).

Thus we specify new rates under constant load when Campus selects 1PC rate, and TV Tower selects $2 \mathrm{PC}$ rate, and profit of the load serving entity is controlled such that to exceed the profit in the initial conditions when TOU rate is specified incorrectly and both customers select the flat rate (1PC). Table 6 gives detailed consideration to characteristics of the initial (described in Section 2) system of rates that is formed after solving the problem (1)-(4) for Moscow oblast. Initial rates are: $1 \mathrm{PC}-5.04$ $\mathrm{Rub} / \mathrm{kW}$; 2PC (nighttime) - $3.67 \mathrm{Rub} / \mathrm{kW}$, semi peak $5.19 \mathrm{Rub} / \mathrm{kW}$, peak - $8.83 \mathrm{Rub} / \mathrm{kW}$. After solving the problem (1)-(4) the optimum rates were specified as follows: $1 \mathrm{PC}-5.17 \mathrm{Rub} / \mathrm{kW}$; 2PC (nighttime) - 3.67 $\mathrm{Rub} / \mathrm{kW}$, semi peak - 4.98 Rub/kW, peak - 6.19 Rub/kW. Calculations were made under the assumption that the load serving entity (LSE) costs and a load of customers do not change.

Results of calculation of the load serving entity profit and payments of customers under different rates are given in Table 6. The rate type is given in bold. This was the base for calculating the load serving entity profit.

Table 6. Comparison of payments at the existing rates and rates adjusted based on the model for optimization of motivating properties of different prices for different types of customers (1)-(4). RF region: Moscow oblast.

\begin{tabular}{|c|c|c|c|c|}
\hline \multirow{2}{*}{ Customer } & \multicolumn{2}{|c|}{ Rates in force } & \multicolumn{2}{c|}{$\begin{array}{c}\text { Demand-response } \\
\text { rates }\end{array}$} \\
\cline { 2 - 5 } & $1 \mathrm{PC}$ & $2 \mathrm{PC}$ & $1 \mathrm{PC}$ & $2 \mathrm{PC}$ \\
\hline Campus & $\mathbf{6 , 3 4 4}$ & 6,168 & $\mathbf{6 , 4 9 0}$ & 6,525 \\
\hline TV Tower & $\mathbf{2 0 , 6 8 1}$ & 24,359 & 20,681 & $\mathbf{2 0 , 0 7 0}$ \\
\hline LSE profit & \multicolumn{2}{|c|}{4,049} & \multicolumn{2}{c|}{4,049} \\
\hline
\end{tabular}

Table 7 presents the results of solving problem (1)-(4) for some RF regions.

Table 7. Payments at selected rates in different regions.

\begin{tabular}{|l|c|c|c|c|c|}
\hline \multirow{2}{*}{ Region } & \multicolumn{2}{|c|}{ Initial rates } & \multicolumn{2}{c|}{ Optimum rates } & \multirow{2}{*}{ LSE Profit } \\
\cline { 2 - 5 } & Campus & TV Tower & Campus & TV Tower & 822 \\
\hline Irkutsk oblast & 4,017 & 12,800 & 4,122 & 12,800 & 2,949 \\
\hline Krasnoyarsk kray & 8,105 & 25,828 & 8,209 & 25,724 & 4,049 \\
\hline Moscow oblast & 6,344 & 20,215 & 6,512 & 20,055 & 2,869 \\
\hline Lipetsk oblast & 8,423 & 26,841 & 8,634 & 26,695 & 4,258 \\
\hline Volgograd oblast & 9,498 & 30,099 & 9,666 & 30,267 & 2,626 \\
\hline Astrakhan oblast & 7,026 & 22,390 & 7,177 & 22,239 & 3,019 \\
\hline Sverdlovsk oblast & 6,906 & 22,007 & 7,056 & 21,857 & 3,208 \\
\hline Chelyabinsk oblast & 6,643 & 21,167 & 6,803 & 21,007 & \\
\hline
\end{tabular}

In our opinion, the implementation of rate rates like this would add 2PC prices stimulating the reduction of peak loads to the system of retail electricity prices. The table shows total payments at the selected rates for the existing system of prices and for the system obtained in the course of optimization and strengthening the demand response properties. In every case, in the course of optimization, the flat rates were growing, and TOU rates decreased. The decrease was mainly observed in the peak period prices. For this reason payment by Campus that selects flat rate in both cases somewhat grows. Payment of TV Tower that initially selects $1 \mathrm{PC}$ rate and then $2 \mathrm{PC}$ rate reduces. Thus, $2 \mathrm{PC}$ rate acquires incentivizing properties. In these circumstances, TV Tower as a customer becomes interested in 2PC rate that would reduce their payment subject to any energy saving activities within the peak zone.

\section{Conclusion}

Development of intelligent technologies motivated the active introduction of new methods for demand-response behavior of consumers, including by controlling retail market prices (rates). There are several approaches to that. One of them is the on-line demand response which implies immediate response of a customer to the changing supply. In our opinion, this approach cannot be implemented in the conditions of the Russian market. The level of smart grid introduction in Russia is rather low, the major share of customers has low rationality and they are not ready to spend time and forces to respond to changeable prices. The proposed model allows demand response within a month or a quarter of the year. The time interval used in our study was a month. The efficiency of the approach is represented by calculations using a model 
for several RF regions for two consumers of different types subject to an unchangeable load curve.

\section{ACKNOWLEDGMENT}

Supported by the Siberian Branch of the Russian Academy of Sciences project №AAAA-A17117030310449-7, grants 019-010-00183, 18-010-00728 from Russian Foundation for Basic Research.

\section{References}

1. N. Zhanng, L.F. Ochoa, D.S. Kirschen, IEEE PES ISGT Europe2011, Investigating the impact of demand side management on residential customers, (2011).

2. A. Fazeli, E. Christopher, C.M. Johnson, M. Gillion, M. Summer, IEEE PES ISGT Europe2011, Investigating the effects of dynamic demand side management within intelligent smart energy communities of future decentralized power system (2011).

3. Worldwide Survey of Network-driven Demand-side Management Projects Research Report No 1. Task $X V$ of the International Energy Agency Demand Side Management Programme. Second Edition. (2008).Available at: http://www.efa.com.au

4. N.I. Aizenberg, E.V. Stashkevich, N.I. Voropai, Izv.RAN. Ener., Coordination of interaction between an electricity supply company and active consumers under optimization of daily load curves, 3, 15, (2016).

5. N. Aizenberg, E. Stashkevich, N. Voropai, Int. J. Pub. Adm., Forming Rate Options for Various Types of Consumers in the Retail Electricity Market by Solving the Adverse Selection Problem, 42(15-16), 1349, (2019).

6. Quarterly Report on European Electricity Markets Market Observatory for Energy, Available at: https://ec.europa.eu/eurostat/statisticsexplained/index.php/Electricity_price_statistics

7. K. Jessoe, D. Rapson, The J. Ind. Ec., Commercial and Industrial Demand Response Under Mandatory Time- of- Use Electricity Pricing, 63.3, 397, (2015).

8. C. Emre, J. D. Fuller, IEEE Tr.PS, Time-of-use pricing in electricity markets under different market structures, 27.3, 1170, (2012).

9. TOU rates Ontario, Available at: https://alectrautilities.com/time-use-rates

10. N. Yaagoubi, H. T. Mouftan, IEEE Tr. SG, Useraware game theoretic approach for demand management, 6(2), 716, (2015).

11. W. Tushar, J. A. Zhang, D. B. Smith, H. Poor, V. S. Thiebaux, IEEE Tr. SG, Prioritizing consumers in Smart Grid: A game theoretic approach, 5(3), 1429, (2014).

12. H. Mohsenian-Rad, V. W. Wong, J. Jatskevich, R. Schober, A. Leon-Garcia, IEEE Tr. SG, Autonomous demand-side management based on game-theoretic energy consumption scheduling for the future smart grid, 1(3), 320, (2010).

13. Decree of RF Government dtd 4/05/2012. No. 442 "On functioning of retail electricity markets, complete or partial limitation of electricity consumption mode".

14. FAA, Report on competition state in Russian Federation for 2018, (2019), Available at: https://fas.gov.ru/documents/685806

15. Decree of RF Government dtd 29/12/2011 No. 1179 (ed. as of 15/05/2019) "On determination and application of uncontrollable electricity prices (power) by quarantee suppliers" (together with "Rules for determination and application of uncontrollable electricity prices (power) by quarantee suppliers").

16. Decree of RF Government dtd 27/12/2010 No. 1172 (ed. as of 10/03/2020) On approving the Rules of wholesale electricity and power market an on alternations to some RF Government Acts on organizing the functioning of the electricity and power wholesale market". 